Research Article

\title{
Effectiveness of P6 Acupressure on Reduction of Nausea, Vomiting \& Retching among Antenatal Women attending Antenatal Clinic at District Hospitals of Sikkim
}

\author{
Kessang Lepcha', Barkha Devi ${ }^{2}$, Mridula Das $^{3}$
}

${ }^{1}$ M. Sc., Nursing Student, ${ }^{2}$ Assistant Professor, ${ }^{3}$ Principal, Sikkim Manipal College of Nursing, Sikkim Manipal University, Gangtok, Sikkim, India.

DOI: https://doi.org/10.24321/2455.9318.202005

I $\quad \begin{array}{lll}\mathbf{N} & \mathbf{F} & \mathbf{O}\end{array}$

Corresponding Author:

Barkha Devi, Sikkim Manipal College of Nursing, Sikkim Manipal University, Gangtok, Sikkim, India.

E-mail Id:

barkhadevi2@gmail.com

Orcid Id:

https://orcid.org/0000-0001-8926-3867

How to cite this article:

Lepcha K, Devi B, Das M. Effectiveness of P6 Acupressure on Reduction of Nausea, Vomiting \& Retching among Antenatal Women attending Antenatal Clinic at District Hospitals of Sikkim. Int J Nurs Midwif Res 2020; 7(1): 24-30.

Date of Submission: 2020-01-23

Date of Acceptance: 2020-05-13
$\begin{array}{llllllll}\mathbf{A} & \mathbf{B} & \mathbf{S} & \mathbf{T} & \mathbf{R} & \mathbf{A} & \mathbf{C} & \mathbf{T}\end{array}$

Background: Nausea vomiting and retching are troublesome symptoms, which occur during the first trimester of pregnancy. Considering the adverse effects caused by most drugs used during pregnancy to control these symptoms, alternative treatments such as acupressure have been suggested in various studies. The present study examined the effectiveness of acupressure wristband at P6 point on nausea, vomiting and retching during pregnancy among Sikkimese women.

Methods: A non-blinded randomized clinical trial conducted in outpatient department of District Hospitals of Sikkim in 2017 among 80 antenatal women having mild nausea, with or without vomiting or retching within $8^{\text {th }}$ to $12^{\text {th }}$ weeks of gestational period. After consecutive sampling, participants were randomly assigned to experimental and control groups comprising 40 women in each group. The experimental group applied the acupressure wrist band and self-assessed symptoms were recorded twice a day as per Rhodes Index Scale. The control group did not receive any intervention but was asked to record the self-assessed symptoms as per Rhodes Index Scale.Data analysis was conducted using SPSS version 15 applying descriptive, and inferential statistical methods.

Result: A significant difference was observed on $5^{\text {th }}, 6^{\text {th }}$ and $7^{\text {th }}$ day after performing the intervention in experimental group as compared to control group. Further, the mean duration, discomfort and frequency of nausea, vomiting and retching scores in experimental group showed significant decrease as compared to the control group $(p<0.001)$.

Conclusion: Acupressure on $\mathrm{P} 6$ point has proved to be effective to reduce the duration, discomfort and frequency of nausea, vomiting and retching.

Keywords: Nausea, Vomiting, Retching, P6 Acupoint, Acupressure Wristband, Pregnancy 


\section{Introduction}

Nausea and vomiting are among the cardinal signs of early pregnancy, recognized since the time of Hippocrates. ${ }^{1}$ Globally $90 \%$ of pregnant women experience nausea and/or vomiting, retching during the first trimester of pregnancy. The problem is time-limited, with onset at fifth week after the Last Menstrual Period (LMP), a peak at 8 to 12 weeks, and resolution by 16 to 18 weeks for most women. ${ }^{2}$ Considering the adverse effects caused by most drugs used during pregnancy to control these symptoms, alternative treatments such as acupressure at P6 or Nei Guan a site for relief of nausea, vomiting \& retching, have been suggested in various studies. ${ }^{3}$

Acupressure is a part of traditional Chinese medicine is actually one of the branches where there is no need to use the needles. ${ }^{4} \mathrm{~A}$ growing desire for the use of this medicine in obstetrics activities is observed. World Health Organization says: sufficient evidence to confirm the effects of acupressure is to be used as part of curing. ${ }^{5}$ Acupressure is used to reduce stress and fatigue and to gain physical comfort and satisfaction. It reduces the costs associated with the disease also. Out of 2,000 pressure points on the body 200 points can be used for treatment. Acupressure is a method which stimulates energy channels below the skin surface. ${ }^{5} \mathrm{P} 6$ or Neiguan-acupoint is the most commonly used acupressure point to achieve the anti-emesis purpose. It is located on the anteromedial aspect of the forearm between the tendons of flexor carpi radialis and palmaris longus muscles, at a distance of three of the pregnant woman's finger-breadths from the distal palmar crease. ${ }^{6}$

Acupressure wristband is the product which is applied at Neiguan point in performing acupressure.$^{6,7}$ It comprises an elastic wristband incorporating a raised and smooth plastic button to apply skin pressure at particular acupoint. Studies have shown a significantly reduced nausea and vomiting among antenatal women by using acupressure wristband at P6 acupoint which is a potential innovation in relieving nausea and vomiting. ${ }^{8}$

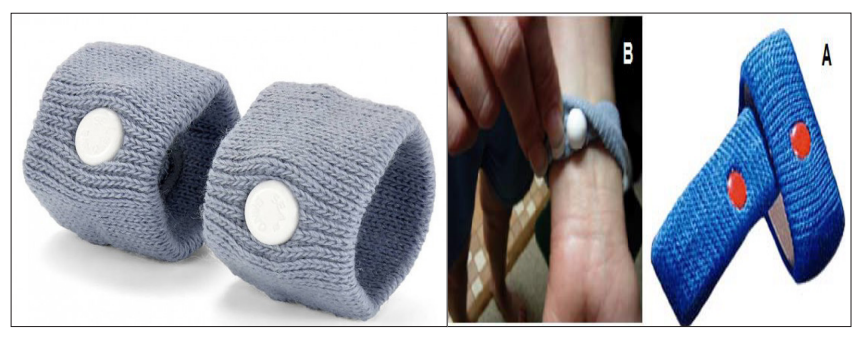

Figure I.Acupressure wristband

Although some pharmacologic anti-emetics are available, but many pregnant women are reluctant to take them for fear of possible teratogenic effects on the fetus during this critical embryogenic period. ${ }^{9}$ Clearly, with no dependable non-pharmacologic treatment available, there is a great need for an intervention that is safe, effective, and free of side effects. In recent years, acupressure has been looked as a treatment modality for possibly meeting these criteria. ${ }^{10}$ It is a non-invasive, inexpensive, and safe treatment that may be successful and self-help option for pregnant women experiencing nausea and vomiting of pregnancy. ${ }^{11-13}$

Nancy MS et al. conducted a quasi-experimental study with posttest-repeated measure design to identify the effect of acupressure by wrist bands on nausea and vomiting of pregnancy among healthy pregnant women in their $1^{\text {st }}$ trimester had at least one episode of nausea, vomiting, or both before their prenatal clinic visit where they were recruited and revealed that the treatment group had significantly less frequency and severity of nausea and vomiting of pregnancy while wearing the wrist bands than did the placebo group hence the study inferred that wristbands with acupressure buttons are a non-invasive, inexpensive, safe and effective treatment for the nausea and vomiting of pregnancy. ${ }^{10}$

Many studies have shown the effect of acupressure on nausea and vomiting related different ailments but studies related to effectiveness of P6 acupressure through wrist band for reduction of nausea, vomiting and retching in pregnancy was very limited in Indian scenario. The investigator didn't document any review of literature related to P6 acupressure with wrist band. Therefore, considering the growing tendency to use acupressure wristband to treat various diseases as well as therapies for nausea and vomiting, ease of use, low cost, safe practice encourages the investigator to evaluate the effect of acupressure on nausea and vomiting among antenatal mother attending antenatal clinic in district hospitals of Sikkim.

\section{Methodology}

It was a 7-days non-blinded randomized clinical trial conducted in outpatient department of District Hospitals of Sikkim among 80 antenatal women having mild nausea, with or without vomiting or retching within $8^{\text {th }}$ to $12^{\text {th }}$ weeks of gestational period from October 2017 to November 2017. The administrative approval and formal permission were sought from the Department of Health and Family Welfare, Government of Sikkim. Self-introduction and establishment of rapport with the participants were done to gain their co-operation. The study was approved by the Institutional Ethics Committee.

The study was conducted in one randomly selected district hospital of Sikkim. On the first day of OPD (before initiation of intervention), each woman enrolled in the study (according to inclusion criteria) was interviewed. Aims and method of data collection were explained to the women. Medical record was reviewed, to obtain the 
socio-demographic data and the obstetrical history. The participants after giving informed consent were requested to fill the baseline information (Day 0 ) on Rhodes Index form. After consecutive sampling, participants were randomly assigned to experimental and control groups

- By using the close envelope containing card written on it P6 acupressure or control group comprising 40 women in each group.

- The envelope was opened by the investigator in the presence of the patient.

- Demonstration on application of wristband at P6 Neiguan point was shown to the experimental group.

- The experimental group was instructed to complete the Rhodes Index of Nausea, Vomiting, and retching Form for 3 days as a pre-test assessment.

- $\quad$ Everyday 7 to 8 antenatal women were included in the study as experimental group till the desired sample achieved.

- Beginning on the morning of the fourth day each antenatal woman in experimental group applied the acupressure wrist band and self-assessed symptoms were recorded twice a day as per Rhodes Index Scale.

The antenatal women were further instructed to leave the wristband in place for the next 24 hours for 4 days except while taking bath, they can remove it, and unless they had any side effects (redness, swelling, and tenderness or paranesthesia). If there are any side effects, the patient was instructed to remove the acupressure wristband for 15 minutes and then replace it and note the time and cause in a diary. Participants in the control group was asked that each morning and evening for 7 consecutive days to fill the Rhodes Index of Nausea, Vomiting and retching Form describing the severity and frequency of symptoms, that occurred. They did not receive any intervention but was asked to record the self-assessed symptoms as per Rhodes Index Scale and if they have taken any antiemetic drugs or any other treatment then it should be noted in the diary and it was checked for the association with the level of nausea, vomiting and retching Data from the first 3 days were used as pre-treatment scores. Data of day 4 was discarded to allow 24 hours for the treatment to take effect. Data from days 5-7 were used to measure treatment effect. Antenatal women were also advised to start a medication if the treatment failed or vomiting is more than 5 times per day and withdraw from the study.

\section{Results and Discussion}

\section{Findings Related to Demographic Data of Antenatal Women}

The result shows that the majority of the antenatal women (55\%) were in the age group of $20-25$ years, $60 \%$ were married in the age group of $20-25$ yrs., $70 \%$ were from urban area, $57.2 \%$ were housewife and $55 \%$ had attended up-to primary level of education and $95 \%$ of the antenatal women were non-vegetarian and $55 \%$ preferred boiled.

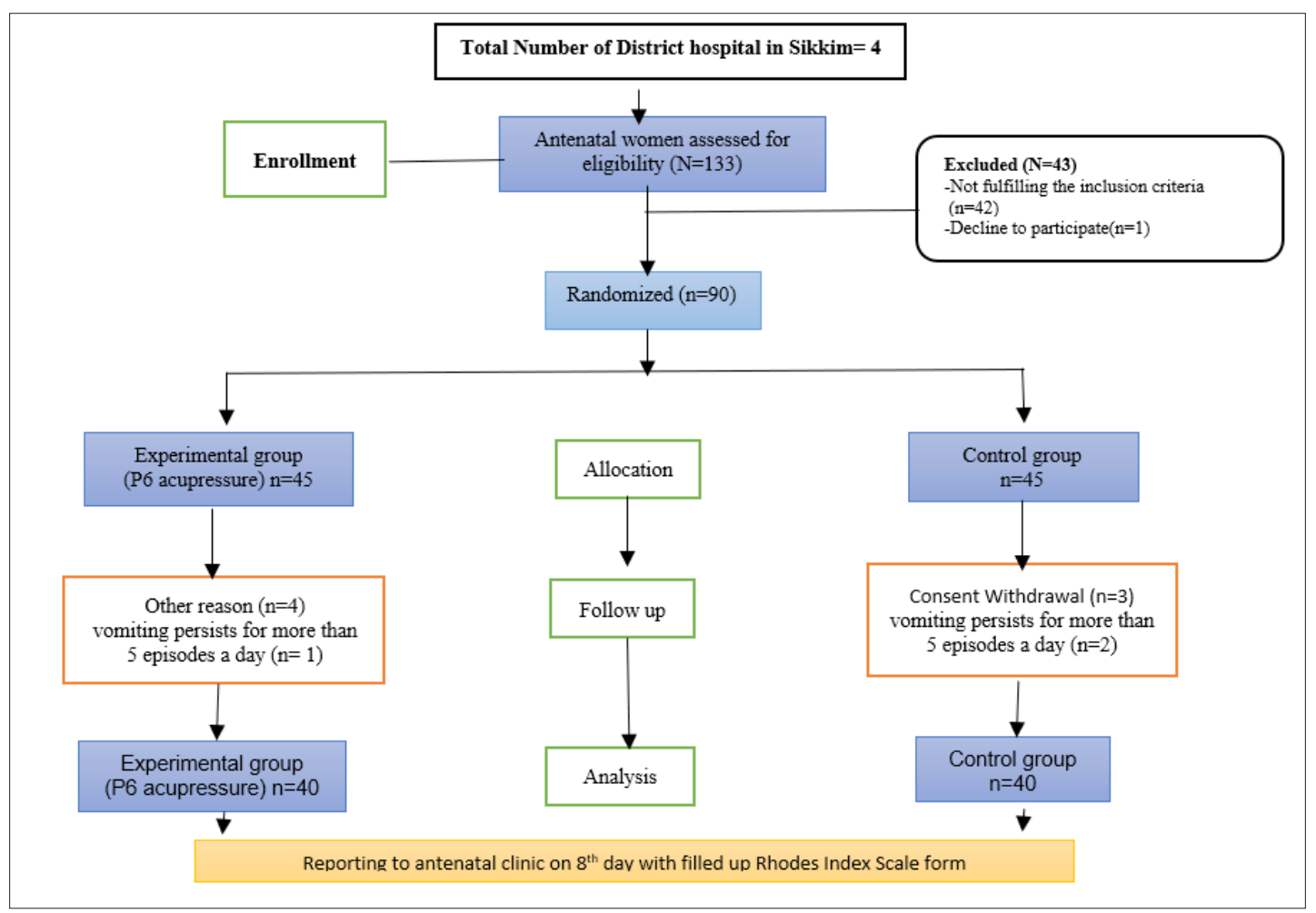

Figure 2.Diagram of non-blinded randomized controlled trial 
The result also shows that the majority of the women i.e. $45 \%$ were primi antenatal women, $30 \%$ had one living children and $20 \%$ had two living children and $5 \%$ had three or more living children in experimental group and in control group 30\% was primi, $45 \%$ had one living children, $25 \%$ had 2 living children. Majority of the women did not have any history of abortion however $30 \%$ in experimental and $25 \%$ in control group had history of abortion. $70 \%$ antenatal women $85 \%$ in control group had unplanned pregnancy. Majority in experimental group i.e. $80 \%$ and in control group $87.5 \%$ knew their LMP whereas $80 \%$ in experimental group and $85 \%$ in controlled group knew their Expected Date of Delivery (EDD).

\section{Findings Related to Obstetrical Profile of the Antenatal Women}

In both the groups, majority of antenatal women were in the $10^{\text {th }}-12^{\text {th }}$ week of gestational period. In experimental group $65 \%$ of the antenatal women were in the $10^{\text {th }}$ week- $12^{\text {th }}$ week of gestational period and in control group $60 \%$ women were in the $10^{\text {th }}$ week $-12^{\text {th }}$ week of gestational period. All $(100 \%)$ antenatal women of experimental and control group had complained of nausea, vomiting, and retching and none $(100 \%)$ were taking any remedies. Majority i.e. $55 \%$ of experimental group had previous history of nausea, vomiting and retching during pregnancy and $70 \%$ of control group also had previous history of nausea, vomiting and retching during pregnancy and none (100\%) of them any remedies for nausea, vomiting, retching in previous pregnancy.

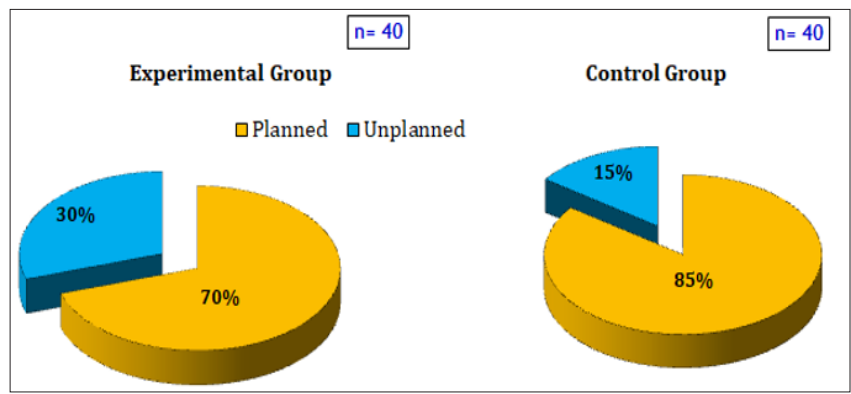

Figure 3.Distribution of antenatal women in terms of their decision regarding pregnancy

Findings Related to Day Wise Comparison of Symptoms at Different Days in Experimental and Control Group

Table I.Comparison of day wise mean score of nausea, vomiting and retching in experimental and control group

$(n=80, n=40)$

\begin{tabular}{|c|c|c|c|c|c|}
\hline \multirow{2}{*}{ Days } & Groups & Mean \pm SD & df & \multicolumn{2}{|c|}{$\begin{array}{c}\text { Independent } \\
\text { t-test }\end{array}$} \\
\cline { 4 - 7 } & & & t & $\begin{array}{c}\boldsymbol{P} \\
\mathbf{( 2 . 0 0 )}\end{array}$ \\
\hline $\begin{array}{c}\text { Day } \\
1\end{array}$ & Experimental & $14.775 \pm 0.97$ & 78 & 0.4 & $\mathrm{P}>0.05$ \\
\cline { 3 - 6 } & Control & $15 \pm 1.01$ & & & \\
\hline
\end{tabular}

\begin{tabular}{|c|c|c|c|c|c|}
\hline \multirow{2}{*}{$\begin{array}{c}\text { Day } \\
2\end{array}$} & Experimental & $14.02 \pm 2.10$ & 78 & 1.25 & $P>0.05$ \\
\hline & Control & $15.02 \pm 0.95$ & & & \\
\hline \multirow{2}{*}{$\begin{array}{c}\text { Day } \\
3\end{array}$} & Experimental & $13.32 \pm 1.88$ & 78 & 1.5 & $P>0.05$ \\
\hline & Control & \multicolumn{2}{|c|}{$14.9 \pm 0.99$} & & \\
\hline \multirow{2}{*}{$\begin{array}{c}\text { Day } \\
4\end{array}$} & Experimental & \multirow{2}{*}{\multicolumn{4}{|c|}{ Measurement not included }} \\
\hline & Control & & & & \\
\hline \multirow{2}{*}{$\begin{array}{c}\text { Day } \\
5\end{array}$} & Experimental & $7.87 \pm 3.80$ & 78 & 3.6 & $\mathrm{P}<0.05$ \\
\hline & Control & $14.9 \pm 1.00$ & & & \\
\hline \multirow{2}{*}{$\begin{array}{c}\text { Day } \\
6\end{array}$} & Experimental & $2.125 \pm 2.04$ & 78 & 15.8 & $P<0.05$ \\
\hline & Control & $14.89 \pm 0.99$ & & & \\
\hline \multirow{2}{*}{$\begin{array}{c}\text { Day } \\
7\end{array}$} & Experimental & $0.7 \pm 1.04$ & 78 & 28 & $\mathrm{P}<0.05$ \\
\hline & Control & $15.04 \pm 1.04$ & & & \\
\hline
\end{tabular}

df $78^{*}=2.00$

The mean symptoms score for day 1, 2, 3 in experimental and control group was found to be similar as evident by t-value $(p>0.05)$ at $d f 78$. This shows that there was no significant difference found initially between the groups. The average mean score was significantly decreased from 14.77 to 0.7 in experimental group after the administration of acupressure wrist band from day 5 to day 7 whereas in case of control group the average mean score remained constant from day 1 to day 7 which shows the effectiveness of P6 acupressure in terms of day wise comparison as evident by t-value $(p<0.05)$ at $d f 78$.

Findings Related to Difference in Mean Duration, Discomfort and Frequency of Vomiting, Nausea and Retching

Table 2.Difference in mean duration, discomfort and frequency of nausea, vomiting and retching before and after applying acupressure wristband in experimental group

\begin{tabular}{|c|c|c|c|}
\hline \multirow{2}{*}{ Assessment } & $\begin{array}{c}|c| \\
\text { Variables } \\
\text { discomfort } \\
\text { and freq- } \\
\text { uency of } \\
\text { nausea }\end{array}$ & $\begin{array}{c}\text { Duration, } \\
\text { Duration, } \\
\text { discomfort } \\
\text { and freq- } \\
\text { uency of } \\
\text { vomiting }\end{array}$ & $\begin{array}{c}\text { Symptoms } \\
\text { of } \\
\text { retching }\end{array}$ \\
\cline { 2 - 4 } & Mean \pm SD & Mean \pm SD & Mean \pm SD \\
\hline $\begin{array}{c}\text { Before applying } \\
\text { acupressure } \\
\text { wristband }\end{array}$ & $26.77 \pm 8.19$ & $9.55 \pm 12.77$ & $5.9 \pm 6.78$ \\
\hline $\begin{array}{c}\text { After applying } \\
\text { acupressure } \\
\text { wristband }\end{array}$ & $6.35 \pm 3.77$ & $4.42 \pm 3.85$ & $2.6 \pm 2.24$ \\
\hline Paired-t-test & $\begin{array}{c}7.43(P< \\
0.05,0.001)\end{array}$ & $\begin{array}{c}0.05,0.001) \\
\text { Ping }\end{array}$ & $3(P<0.05)$ \\
\hline
\end{tabular}

df $39=2.02, P<0.05,0.001$. 
The mean nausea $(26.77 \pm 8.19)$, vomiting $(9.55 \pm 12.77)$ and retching score $(5.9 \pm 6.78)$ before applying $\mathrm{P} 6$ acupressure wristband was higher than the mean nausea $(6.35 \pm 3.77)$, vomiting (4.42 \pm 3.85$)$ and retching score (2.6 \pm 2.24$)$ after applying acupressure wristbandin terms of duration, discomfort and frequency and this difference was found statistically significant as evidenced from paired t test-value for duration, discomfort and frequency of nausea (5.4, $p<0.05,0.001)$, vomiting $(7.43, p<0.05,0.001)$, frequency and symptoms of retching $(3, p<0.05)$ at df $39(2.02)$ at 0.05 as well as 0.001 level of significance.

The mean score for nausea $(26.77 \pm 8.19)$, vomiting $(10.09 \pm 2.38)$ and retching $(5.82 \pm 0.90)$ was remain similar on day1,2,3 over the time with mean score of nausea (27.5 \pm 2.58$)$, vomiting $(10.61 \pm 14.08)$, and retching score $(5.5 \pm 1.5)$ on day $5,6,7$ in terms of duration, discomfort and frequency and this difference was also not found statistically significant.

Table 3.Difference in mean duration, discomfort and frequency of vomiting, nausea and retching in control group

\begin{tabular}{|c|c|c|c|}
\hline \multirow{2}{*}{ Assessment } & \multicolumn{3}{|c|}{ Type of Variable } \\
\cline { 2 - 4 } & $\begin{array}{c}\text { Duration, } \\
\text { discomfort } \\
\text { and } \\
\text { frequency } \\
\text { of Nausea }\end{array}$ & $\begin{array}{c}\text { Duration, } \\
\text { discomfort } \\
\text { and } \\
\text { frequency of } \\
\text { Vomiting }\end{array}$ & $\begin{array}{c}\text { Symptoms } \\
\text { of } \\
\text { Retching }\end{array}$ \\
\cline { 2 - 4 } & Mean \pm SD & Mean \pm SD & Mean \pm SD \\
\hline $\begin{array}{c}\text { Assessment } \\
\text { on Day 1-3 }\end{array}$ & $27.3 \pm 2.99$ & $10.09 \pm 2.38$ & $5.82 \pm 0.90$ \\
\hline $\begin{array}{c}\text { Assessment } \\
\text { on Day 5-7 }\end{array}$ & $27.5 \pm 2.58$ & $10.61 \pm 14.08$ & $5.5 \pm 1.5$ \\
\hline Paired-t-test & 0.09 & 0.09 & 0.6 \\
\hline
\end{tabular}

Findings Related to Test for Equality of Variances for Reduction of Nausea, Vomiting \& Retching among Antenatal Women in Terms of Overall Score

Table 4.Paired samples test for nausea, vomiting and retching severity scores irrespective of time of assessment in experimental group

\begin{tabular}{|c|c|c|c|c|c|c|c|c|}
\hline \multirow{3}{*}{ Group } & \multicolumn{5}{|c|}{ Paired Differences } & \multirow{3}{*}{$' t '$} & \multirow{3}{*}{ df } & \multirow{3}{*}{$\begin{array}{c}\text { Sig. } \\
\text { (2-tailed) }\end{array}$} \\
\hline & \multirow[t]{2}{*}{ Mean } & \multirow{2}{*}{$\begin{array}{l}\text { Std. } \\
\text { Deviation }\end{array}$} & \multirow{2}{*}{$\begin{array}{l}\text { Std. Error } \\
\text { Mean }\end{array}$} & \multicolumn{2}{|c|}{$\begin{array}{l}\text { 95\% Confidence Interval } \\
\text { of the Difference }\end{array}$} & & & \\
\hline & & & & Lower & Upper & & & \\
\hline $\begin{array}{c}\text { Experimental group } \\
\text { Pre-post }\end{array}$ & 24.500 & 5.267 & .833 & 22.815 & 26.185 & 29.418 & 39 & .000 \\
\hline $\begin{array}{l}\text { Control group } \\
\text { Pre-post }\end{array}$ & 0.025 & 2.082 & 0.329 & -.641 & .691 & .076 & 39 & 0.940 \\
\hline
\end{tabular}


The findings of the present study also reveals that there was an effectiveness of P6 acupressure band in reduction of retching as the mean score of the retching in experimental group significantly decreased after applying acupressure wristband, the severity of retching as well as the frequency was significantly decreased in the experimental group .The finding is consistent with the Suzan EM et al. ${ }^{8}$ who stated in the study that there was a significant decrease in the average mean scores of retching and the total score from the baseline to $4^{\text {th }}$ day and concluded that using P6 acupressure has an effective role in reducing retching episodes in hyperemesis gravidarum.

The findings in the present study reveals that the there was no statistical significant difference in the characteristics of the nausea, vomiting and retching score between the P6 acupressure group and the control group before application of acupressure wristband, but there was a significant decrease in the average mean scores of nausea, vomiting and retching and the total score after applying P6 acupressure band. The findings were also consistent with the study conducted by Werntoft $E$ and Dykes $A K^{18}$ and found that acupressure using sea-bands daily for two weeks (removed only when showering) significantly reduced nausea in healthy pregnant women as compared with both control (no antiemetic) and placebo (Sea-Bands at non-meridian) groups $(n=60)$. Jemigorn $M$ and Phupong $\mathrm{V}^{18}$ who conducted a randomized study to evaluate the effect of acupressure and vitamin B6 to relieve nausea and vomiting in pregnancy, found that the acupressure using sea-bands for 24 hours a day for five days reduced nausea and vomiting in 60 pregnant women compared to vitamin B6 and placebo wrist bands. Molassiotis AM et al. ${ }^{6}$ found that acupressure using Sea-Bands continuously for five days significantly reduced vomiting, and retching in patients with breast cancer receiving chemotherapy when compared to a control group receiving standard care $(n=36)$.

\section{Conclusion}

It is concluded that P6 acupressure was an effective measure in reducing nausea, vomiting and retching episodes in antenatal women. Therefore, inclusion of P6 acupressure as an intervention may improve patient care outcomes. These measures might be effective in reducing the use of anti-nausea and anti-vomiting drugs and their posed risks during pregnancy. P6 acupressure is a non-invasive method that may have a place as prophylactic antiemetic therapy during obstetrical and gynecological surgery.

\section{Acknowledgment}

The researcher thanks all the participants of the study for their kind cooperation.

\section{Conflicts of Interest: None}

\section{References}

1. Christine N, Martha S. Introduction to Maternal and Child Health Nursing. $1^{\text {st }}$ Ed. Lippincott, New York.

2. Koren G, Boskovic R, Hard M et al. Mothers risk - PUQE. (pregnancy-unique quantification of emesis and nausea) scoring system for nausea and vomiting of pregnancy. American Journal of Obstetrics \& Gynecology 2009; 186(5): 228-231.

3. Lacroix R, Eason E, Melzack R. Nausea and vomiting during pregnancy: A prospective study of its frequency, intensity, and patterns of change. Am J Obstet Gynecol 2000; 182: 931-937.

4. Yeong HS. Tae IK, Mi SS et al. Effect of acupressure on nausea and vomiting during chemotherapy cycle for Korean postoperative stomach cancer patients. Cancer Nursing 2004; 27(4): 267-274.

5. Azza AAEH. Effect of acupressure on morning sickness at Cairo university hospital. Lambert Academic Publishing.

6. Molassiotisa AM, Helinb R, Dabboura S. The effects of P6 acupressure in the prophylaxis of chemotherapyrelated nausea and vomiting in breast cancer patients. Nottingham, UK 2006; 71(2): 548-559.

7. Sabri F. Acupressure and Ginger to Relieve Nausea and Vomiting in Pregnancy: a Randomized Study. Iran Red Crescent Med J 2013; 15(9): 854-861.

8. Suzan EM, Mohammad AE, Alaa ME et al. Effect of nurses using for P6 acupressure on nausea, vomiting and retching in women with hyperemesis gravidarum. Journal of Nursing and Health Science 2015; 4(4): 1-9.

9. Ornstein M, Einarson A, Koren G. Bendectid/diclectin for morning sickness: A Canadian follow-up of an American tragedy. Reproductive Toxicol ogy 1995; 9: 1-6.

10. Nancy MS, Joyce F, Janet GB et al. effect of acupressure by sea-bands on nausea and vomiting of pregnancy. Journal of Obstetric, Gynecologic \& Neonatal Nursing 2001; 30(1): 61-70.

11. Movahedi M, Ghafari S, Nazari F et al. The effects of acupressure on pain severity in female nurses with chronic low back pain. Iranian Journal of Nursing and Midwifery Research 2017; 22: 339-342.

12. Chung UL, Hung LC, Kuo SC et al. Effects of LI4 and BL 67 acupressure on labor pain and uterine contractions in the first stage of labor. J Nurs Res 2003; 11(4): 251-260.

13. Forouhari S, Ghaemi SZ, Roshandel A et al. The effect of acupressure on nausea and vomiting during pregnancy. Researcher 2014; 6: 27-34.

14. Norheim JA, Jesman Pedersen E, Fønneb $\emptyset$ V et al. Acupressure treatment of morning sickness in pregnancy. Scandinavian Journal of Primary Health Care 2001; 19(1): 43-47. 
15. Robertshawe P. Effect of acupressure on nausea and vomiting during pregnancy. Complementary Therapies in Clinical Practice 2008; 14: 46-52.

16. Salem S. Effect of wrist acupressure on the first trimester pregnant women with morning sickness. Unpublished doctoral dissertation, faculty of nursing, in Shams University. 2009.

17. Werntoft E, Dykes AK. Effect of acupressure on nausea and vomiting during pregnancy. Journal of Reproductive Medicine 2001; 46(9): 835-839.

18. Jamigorn $\mathrm{M}$, Phupong V. Acupressure and vitamin B6 to relieve nausea and vomiting in pregnancy: a randomized study. Arch Gynaecology Obstet 2007; 276(3): 245-249. 